International Journal of Design and Manufacturing

Technology (IJDMT),

ISSN 0976 - 6995(Print), ISSN 0976 - 7002(Online)

Volume 1, Issue 1, January-December (2010), pp. 24-44

(C) IAEME, http://www.iaeme.com/ijdmt.html

\title{
SIMULATION OF SPRAY DRYER CHAMBER BY THE STANDARD K-E, RELIABLE K-C AND REYNOLDS STRESS MODELS USED IN THE PRODUCTION OF THERMAL SPRAY POWDERS
}

\author{
Qasim. Murtaza* \\ Delhi Technological University, (Formerly DCE), Govt. NCT, Delhi-42, India
}

\begin{abstract}
Spray-drying technique which is an uninterrupted process of drying slurry is becoming an important apparatus in the production of thermal spray powders. There are several hundred commercial powders specifically developed for the various spray drying process; metals, metals alloys, ceramics, carbides and polymers. Thermal spray powders are produce using a mixed type spray dryer, as it gives higher temperature exposure and more residence time of spray to evaporate in the drying chamber. To improve the performance and prediction of process parameters of spray dryer, the CFD analysis was done, the Standard K- $\epsilon$, Reliable K- $\epsilon$ and Reynolds Stress Model models were used to predict velocity profiles and temperature profile for the drying chamber. Different model results were compared, studied and compared with experimental results. The Reliable K- $\epsilon$ method is found to have good agreement with the experiment data to predict the velocity and, mimicked the temperature profile of the drying chamber.
\end{abstract}

Key words: Spray Dryer, Thermal Powder, CFD

\section{INTRODUCTION}

The thermal spray powder properties and characteristics have a direct impact on thermal spray coating quality, ease of application and performance in its end use thus depend upon the methods of manufacture, purity, morphology and particle size distribution which yields free flow powder $[\mathbf{1 , 2}]$. Therefore thermal spray powders should be free flowing with narrow distribution size and have spherical shape [3]. These thermal spray powders can be used to produce thermally sprayed coatings to improve the serviceability of engineering components and biomedical implants [5]. This process involves powders been carried into a thermal spray combustion compartment which heats/melts and then propels it onto a substrate as a coating. This coating provides the substrate with a protective layer from wear, corrosion and thermal effects. Thermal spray powders can be coated by High Velocity Oxy-Fuel (HVOF) or Plasma spray techniques [5]. These thermal spray coatings have lenticular or lamellar grain structure 
International Journal of Design and Manufacturing Technology (IJDMT), ISSN 0976 - 6995(Print), ISSN 0976 - 7002(Online) Volume 1, Issue 1, January-December (2010), @ IAEME

due to quick solidification of small globules, and are flattened due to them striking a cold surface at high velocities. In most cases, the in-flight particles are molten or partially molten before impact and solidify a few microseconds after impact and this depends upon the particle size and shape during the production of the thermal spray powder. In general, there are four basic methods of producing thermal spray powders; crushing, agglomeration, chemical and atomisation [6]. Each method can be further sub-divided and powders can also be produce by various combinations from each group. Among all, spray-drying is becoming an important tool in the production of thermal spray powders $[\mathbf{7 , 8}]$. The Spray drying technique is a continuous process of drying slurry. The drying process involves the atomisation of a feedstock which is either being a solution, suspension or paste into a spray, and then the interaction between the spray and the hot air medium results in moisture evaporation. The resulting dried product converts either into a free flowing powder, granule or agglomerate type of material and its type depends upon the physical and chemical properties of the feedstock, dryer design and its operating parameters [9]. The dried powder can be easily controlled to its precise quality values such as particle size, particle size distribution, bulk and particle density, friability, dispersibility and flowability with careful choice of its drying parameters [10]. There are several hundred commercial powders specifically developed for the various spray drying process; metals, metals alloys, ceramics, carbides and polymers [7-10]. Thermal spray powders are produce using a mixed type spray dryer, as it gives higher temperature exposure and more residence time of spray to evaporate in the drying chamber. Wherein the external-two fluid nozzle of the mixed spray dryer system is preferable in producing thermal spray powders so as to avoid clogging and to control powder size by varying atomising pressures and this nozzle atomisation are generally form coarse particle powders with good flowability and the variation of the pressure allows control over the feed rate and the spray characteristics [11]. Therefore, The spray drying temperature profile that controls morphology and particle size distribution which yields free flow powders have a direct impact on thermal spray coating quality, ease of application and performance in its end use [11]. A mixed spray drying process can be divided into four stages [12] - Atomisation, Spray-air contact, Spray evaporation and Product separation. The air mixing system investigated in this research was of a mixed flow type. It incorporates both co-current and countercurrent air mixing systems. In the air mixing flow system, the feed been atomized and hot air comes in contact in the opposite directions. Figure 1 shows the exact layout of the mixed flow system used in the present research. Therefore the hot air enters from the top of the drying chamber and the feed spray from the bottom, both meet near the top of the chamber (evaporation occurs) and then the feed and air fall back down towards the bottom of the camber. The dried powder is collected at the bottom of the drying chamber. The feed is sprayed into the coolest gas first, and gradually flows towards the hottest zone near the top of the chamber decreasing the instantaneous rate of drying and directionally producing a higher density product. Therefore the system can be used for heat sensitive products where coarse powder requirements necessitate the use of nozzle atomizers. The particle trajectory is increased (double as compare with co-current or counter-current flow mixing systems), allowing for extra drying time, thus decreasing the overall spray dryer height required. 
International Journal of Design and Manufacturing Technology (IJDMT), ISSN 0976 - 6995(Print), ISSN 0976 - 7002(Online) Volume 1, Issue 1, January-December (2010), @ IAEME

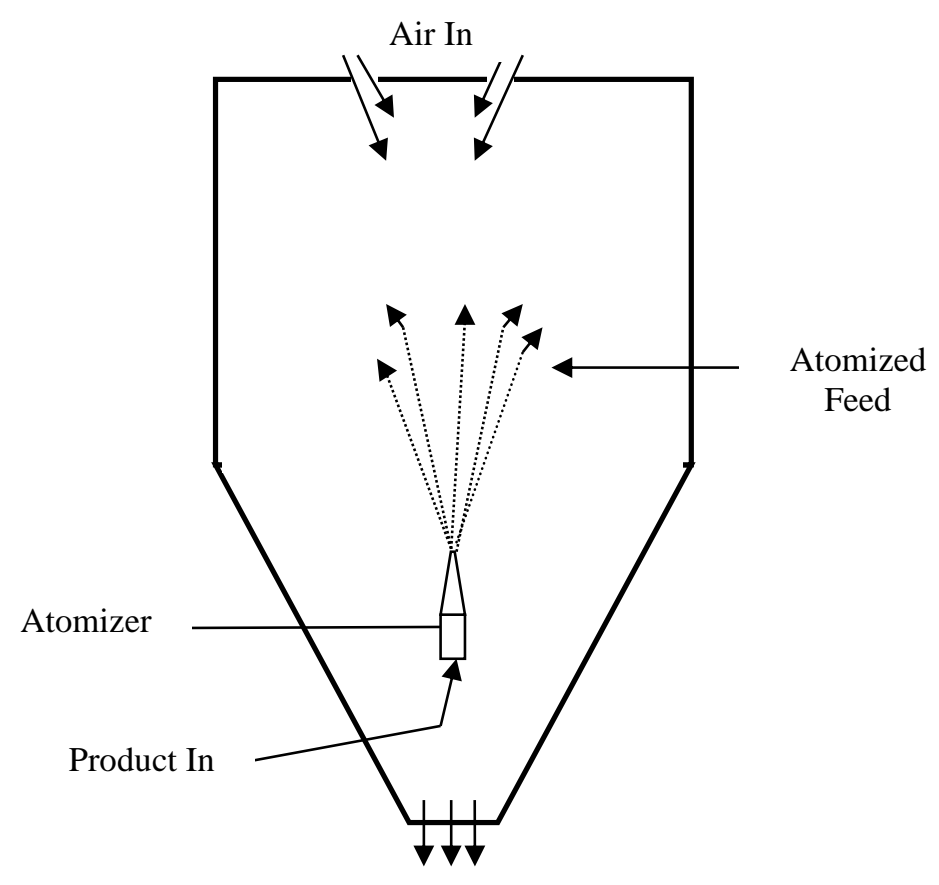

Air and Product Out

Figure 1: Mixed air-flow pattern in a spray dryer used in the present research.

The spray-airflow mixing can be defined as the spray behaviour such as trajectories, evaporation rate, and residence time in the drying chamber $[\mathbf{1 3 , 1 4}]$. Drying of the droplets is carried out in two stages. First, diffusion of moisture from within the droplet maintains a saturated condition, that means the temperature at the droplet surface approximates to the wet bulb temperature of the drying air, and as long as this lasts evaporation can be maintained at a constant rate. It is known as the constant rate period or the first period of drying [1]. When the moisture content becomes too low to maintain saturated conditions and it reaches a critical point where a dried shell forms on the droplet surface, evaporation now becomes dependent upon the rate of moisture diffusion through the dried surface shell. The thickness of the dried shell increases with time, causing a decrease in the rate of evaporation. This is called the falling rate of or the second period of drying $[\mathbf{1 , 1 3}]$. This is described by the drying rate curve shown in Figure 2. The droplet residence time in the chamber depends upon the drying chamber design and the air flow rates (co-current, counter current and mixed current) [13]. Different products can exhibit different evaporation characteristics, some tend to expand, and others collapse, fracture, leading to porous, irregularly shaped particles [15], as shown in Figure 3. Others maintain a constant spherical shape or even contract, thus the particles become more dense. The extent of any change in particle shape, and hence the dried-powder characteristics, are closely connected to the drying rate [15]. The thermal spray process requires its powders to be spherically shaped and have a uniform size distribution so as to achieve maximum flowablity characteristics [7]. 
International Journal of Design and Manufacturing Technology (IJDMT), ISSN 0976 - 6995(Print), ISSN 0976 - 7002(Online) Volume 1, Issue 1, January-December (2010), @ IAEME

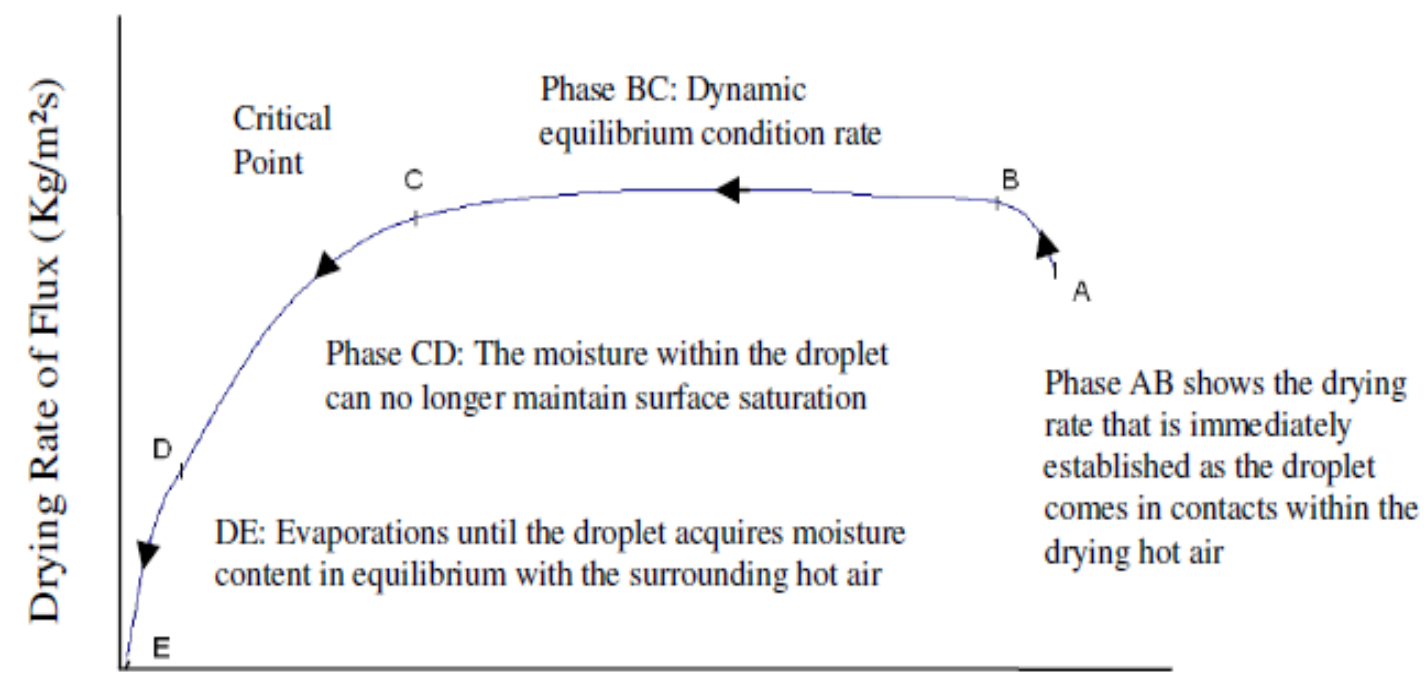

Moisture Content (\%)

Figure 2: Drying rate curve [12]

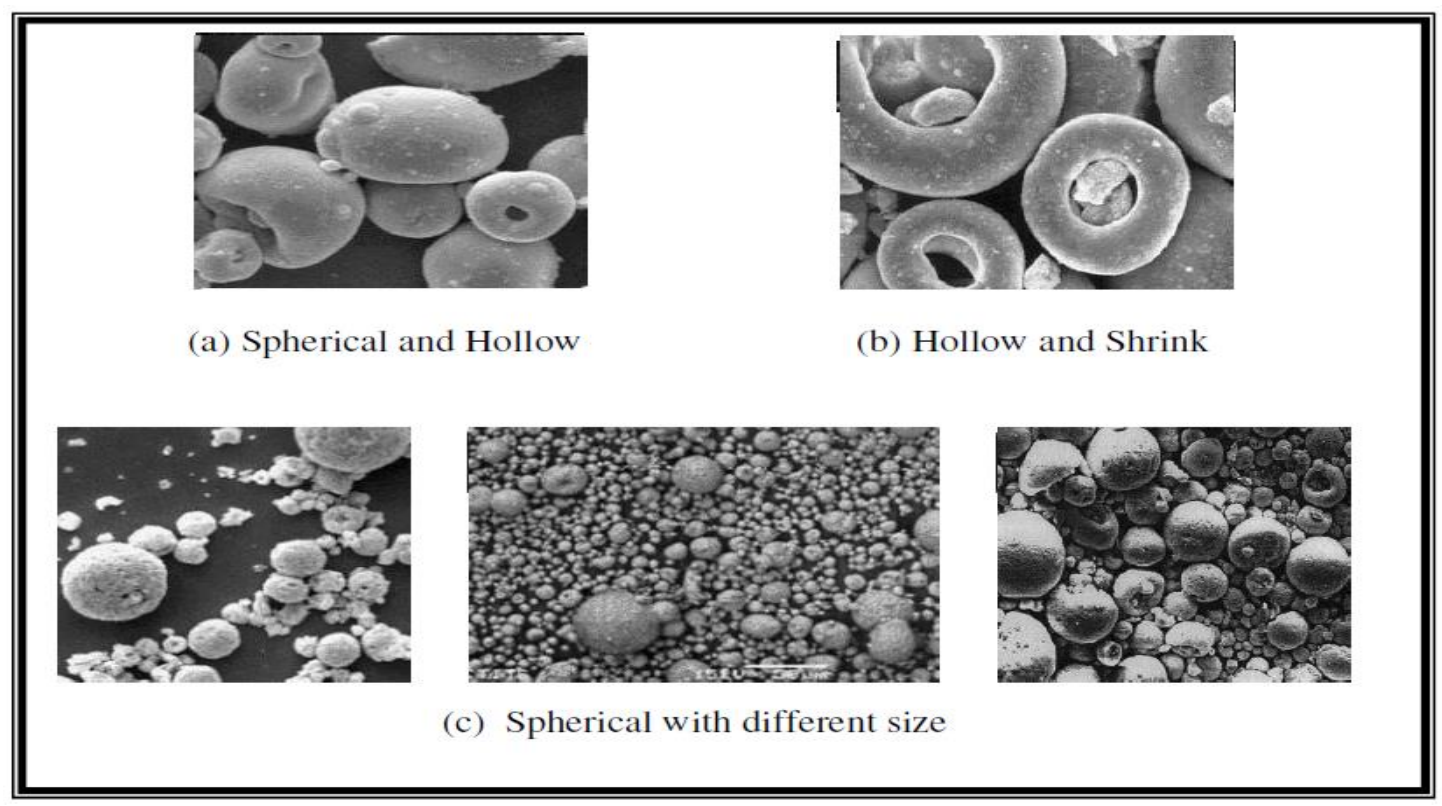

Figure 3: Different shapes of spray dried thermal spray powder [15]

To improve the performance of spray dryer, over the past decades research in this field of spray dryer modelling has primarily dealt with the practical effectiveness of spray dryers in various industries. These designs are mainly empirically and artistically in nature. However, experiments on full-scale spray dryer posses major difficulties, not only because of their large sizes and massive costs involved, but also because of their complex and hostile environment in which to measure the velocity of hot air, temperature profiles and particle thermal histories within the drying chamber. On the other hand, these are essential to understand the spray drying process completely. This understanding will lead to good productivity, low energy consumption and high final product quality. These short comings are encouraged and attracted to take this present study of a full-scale spray dryer simulations using computational fluid dynamics (CFD) techniques. 
International Journal of Design and Manufacturing Technology (IJDMT), ISSN 0976 - 6995(Print), ISSN 0976 - 7002(Online) Volume 1, Issue 1, January-December (2010), @ IAEME

\section{MODELLING OF DRYING CHAMBER OF THE SPRAY DRYER}

A commercial Niro-Minor spray dryer used modelled in the present research. The drying chamber is $800 \mathrm{~mm}$ in diameter, with a $600 \mathrm{~mm}$ cylindrical height and a conical based. The cone angle is 60 degrees. All of the internal surfaces are made of smooth stainless steel AISI 316. Air enters from the top and leaves the base of the chamber through a duct, which connects the chamber base to the cyclone. The chamber is insulated so that heat loss is minimised. CFD analysis of the drying chamber of spray dryer, the following steps were used; geometry creation, meshing, solver and postprocessing. The drying chamber of spray dryer geometry was created in the Gambit pre-processor which is an integrated packaged for CFD analysis. The drying chamber geometry was accurately created using vertices, lines and then connected faces. The dryer chamber geometry model was created using 4 quadrilateral connected faces respectively due to complexity of their shapes so that forced quadrilateral map meshing scheme would be applied. The main spray chamber was meshed with 63000 quadrilateral elements (Figure 4). The major challenge here was the meshing of the very small spray dryer injector (air/fluid nozzle) $0.75 \mathrm{~mm}$ which required 10 elements compared to the large drying chamber (1.6 $\mathrm{m}$ in height). To over come this problem the both side grading method was used to give proper number of element to capture the full effect of inlet condition without the limitation of the computer facilities. The successive ratio of both side grading was 1.02 .

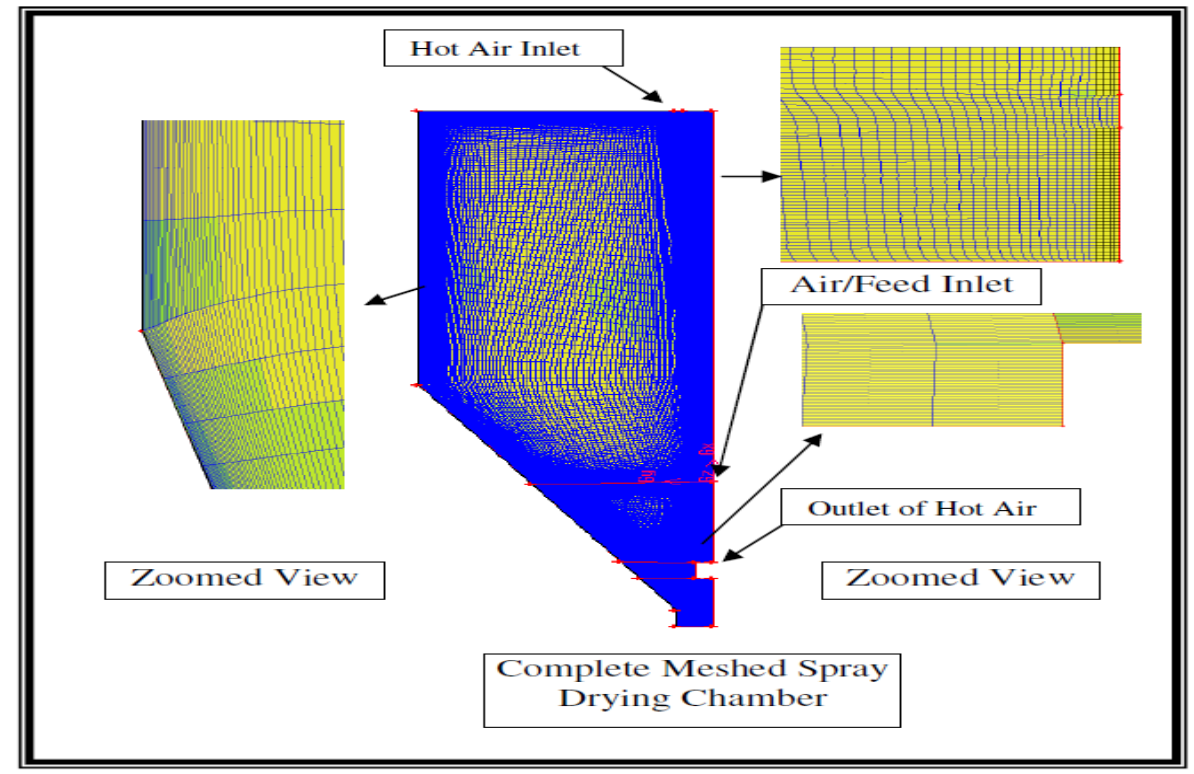

Figure 4: Mixed mesh of 2D axis-symmetric spray dry chamber

As a flow is a continuous domain and is defined by discretion. The flow salient features (such as shear layer, separated region, shock waves, and mixing zones) are depended on the density and distribution of nodes in the mesh. In many cases poor resolution in critical region could dramatically alter the flow characteristics [16-18]. Therefore, a small boundary in the spray dryer model such as inlet of the hot air compared with other boundaries, was meshed using 10 nodes and all other inlet and outlet boundaries were more than 20 nodes. The mesh was checked in the GABMBIT 2.1 program which was based on Equi-angle skew techniques and can be described by. 
International Journal of Design and Manufacturing Technology (IJDMT), ISSN 0976 - 6995(Print), ISSN 0976 - 7002(Online) Volume 1, Issue 1, January-December (2010), (C) IAEME

$$
\max \left[\frac{\theta_{\max }-\theta_{e}}{180-\theta_{e}}, \frac{\theta_{e}-\theta_{\min }}{\theta_{e}}\right] \text {---------------------Equation }
$$

where, $\theta_{\max } \theta_{\min }, \theta_{e}$ are the largest, smallest and equiangular angle face ( 60 for triangles and 90 for square), the quality of mesh is measured by the skewness range. The poor quality of grid will cause in accurate solutions and / or slow convergence [16]. Initially meshing using various strategies failed on one or both of the above points, which meant that the mesh model was gird dependent. Later in models edge, grading on one or both sides and Winslow smoothing scheme were applied to get the desired quality of mesh [18]. The spray dryer was meshed axis-symmetrically due to it symmetric shape and to reduce calculation times. The main spray chamber was meshed with 63000 quadrilateral elements. However, no cells were found with a skewnness more than 0.5 . Therefore, it is very important to check the quality of the resulting mesh, because it properties such as skewness can greatly affect the accuracy and robustness of the CFD solution. The quality of a mesh plays an important role in the accuracy and stability of the CFD results which is based on node point distribution, smoothness and skewness. The FLUENT 6.2 solver was used in the main drying chamber of the spray dryer modelling. The drying chamber was modelled for the temperature and velocity profile to initiate the atomisation in the spray dryer. Figure shows 5 the brief steps of it.

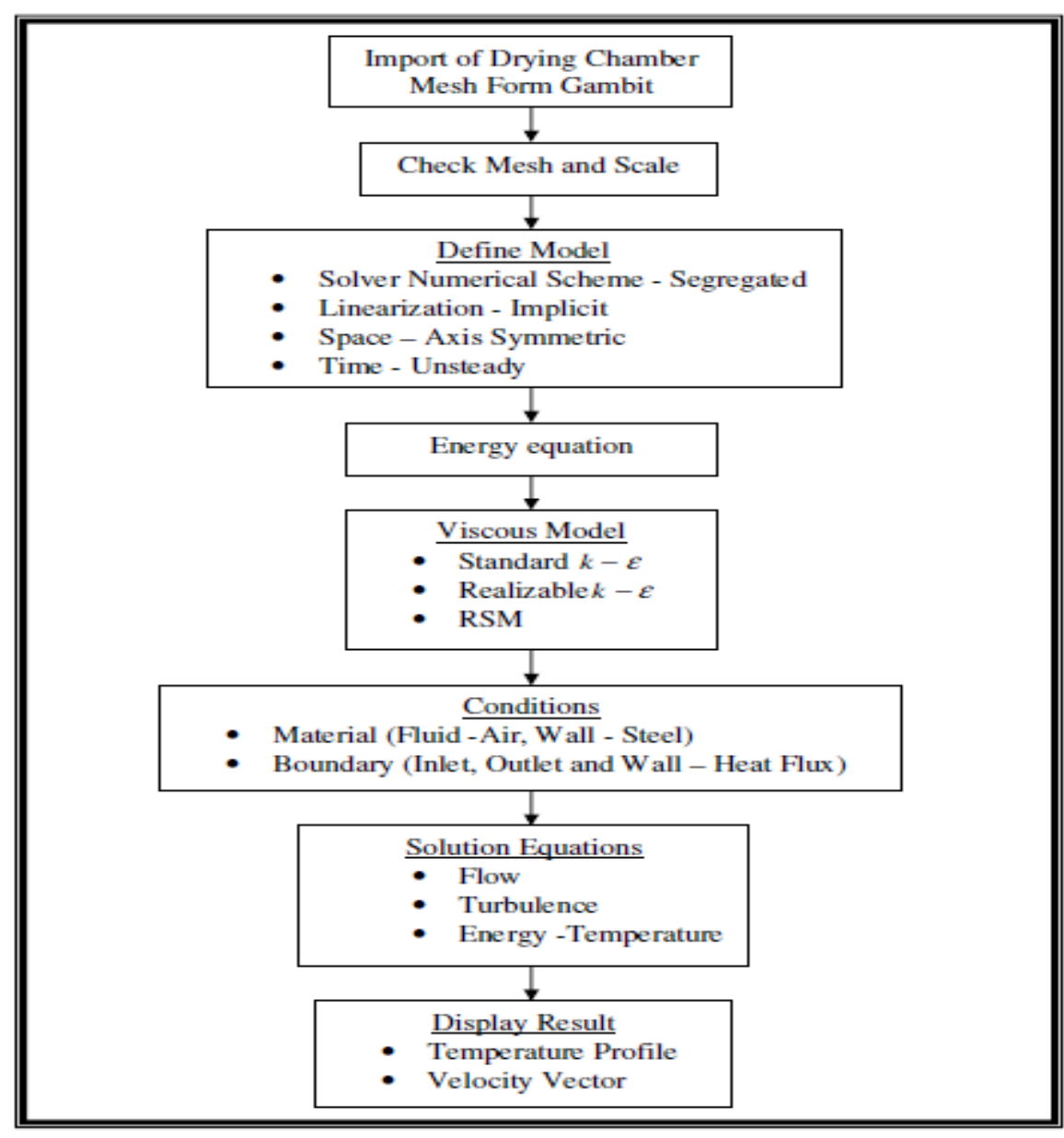

Figure 5: The flow path for drying chamber of the spray dryer simulation for temperature and velocity profile 
International Journal of Design and Manufacturing Technology (IJDMT), ISSN 0976 - 6995(Print), ISSN 0976 - 7002(Online) Volume 1, Issue 1, January-December (2010), @ IAEME

General transport equations for mass and momentum and energy were used in the modelling of spray dryer in the FLUENT software are given below;

$$
\frac{\partial}{\partial t} \int_{V} \rho \phi d V+\oint_{A} \rho \phi V . d A=\quad \oint_{A} \Gamma \nabla \phi . d A+\int_{V} S_{\phi} d V \text {-------Equation C.1 }
$$

Unsteady convection diffusion generation

Where, $\phi$ is a property per unit mass, $\rho$ density, $\mathrm{V}$ control volume, A surface area, and $\nabla$ gradient of $\phi, \Gamma$ diffusion coefficient $\phi$, and $S_{\phi}$ surface of $\phi$ per unit volume.

These partial differential equations are discretized into a system of algebraic equations by finite volume method (FVM). These algebraic equations are then solved numerically to give a solution to the problem.

\subsection{Mass conservation equation}

The general equation for conservation of mass, or continuity equation is as follows:

$$
\frac{\partial \rho}{\partial t}+\nabla \cdot(\rho \nu)=S_{m} \text {-----------------------------------Equation C.2 }
$$

This general form of the mass conservation equation is valid for incompressible as well as compressible flows. The source $S_{m}$ is the mass added to the continuous phase from the dispersed second phase (for an example in this research due to vaporisation of liquid droplets) and any other defined sources.

\subsection{Momentum conservation equation}

The general Conservation of momentum is given by:

$$
\frac{\partial}{\partial t}(\rho \nu)+\nabla \cdot(\rho \nu \rho)=-\nabla p+\nabla \cdot(\bar{\tau})+\rho g+\rho \text {-----------------Equation C.3 }
$$

where $p$ is the static pressure, $\bar{\tau}$ is the stress tensor, and $\rho \tilde{g}$ and $\tilde{F}$ are the gravitational body force and external body forces (that arise from the interaction with the dispersed phase), respectively.

The stress tensor $\overline{\bar{\tau}}$ can be described by:

$$
\overline{\bar{\tau}}=\mu\left[\left(\nabla \stackrel{\rho}{\nu}+\nabla \rho^{T}\right)-\frac{2}{3} \nabla \cdot \rho_{I}\right.
$$

where $\mu$ is the molecular viscosity, $I$ is the unit tensor, and the second term $\left(\frac{2}{3} \nabla . \rho^{\prime}\right)$ on the right hand side is the effect of volume dilation.

\subsection{Energy equation}

General energy equation is as follows;

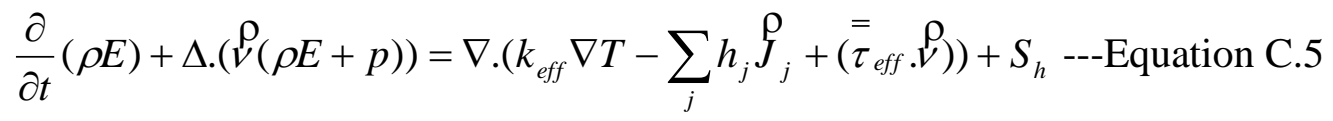


International Journal of Design and Manufacturing Technology (IJDMT), ISSN 0976 - 6995(Print), ISSN 0976 - 7002(Online) Volume 1, Issue 1, January-December (2010), @ IAEME

where $k_{\text {eff }}$ is the effective conductivity defined according to the turbulence model and $\tilde{J}_{j}$ is the diffusion flux of species $j$. The first three terms on the right-hand side of Equation C.5 resent energy transfer due to conduction, species diffusion, and viscous dissipation, respectively. $S_{h}$ includes the heat of chemical reaction, and any other volumetric heat sources is defined.

Where,

$$
E=h-\frac{p}{\rho}+\frac{V^{2}}{2}, \quad h_{j}=\int_{T r e f}^{T} C_{p, j} d t
$$

Where, $p$ is the given pressure, $\rho$ is the density of gas, $V$ is the velocity, $C_{p}$ is heat at the constant pressure, and sensible enthalpy $h$ is defined for ideal gases. Sensible enthalpy $h$ is defined for ideal gases as $h=\sum_{j} Y_{j} h_{j}$, and $Y_{j}$ is the mass fraction of species $j$ and $T_{r e j}$ is $298.15 \mathrm{~K}$.

\subsection{Discretisation (FVM)}

Discretisation of the fluid flow governing equations can be illustrated simply by considering the steady-state conservation equation for transport of a scalar quantity $\phi$. This can be written in integral form for an arbitrary control volume $V$ as follows:

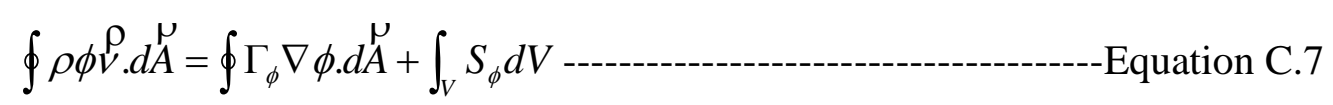

Where,

\begin{tabular}{|c|c|}
\hline$\rho$ & Density \\
\hline$\nu$ & Velocity Vector \\
\hline$d A$ & Surface area vector \\
\hline$\Gamma_{\phi}$ & Diffusion coefficient $\phi$ \\
\hline$\nabla \phi$ & Gradient of $\phi$ \\
\hline$S_{\phi}$ & Surface of $\phi$ per unit volume \\
\hline
\end{tabular}

\subsection{THE STANDARD $k-\varepsilon$ MODEL}

The turbulence kinetic energy $k$ and its rate of dissipation $\varepsilon$ are obtained from the following transport equations:

The general transport equations for the Standard $k-\varepsilon$ model are as follow:

$$
\frac{\partial}{\partial t}(\rho k)+\frac{\partial}{\partial x_{i}}\left(\rho k u_{i}\right)=\frac{\partial}{\partial x_{i}}\left[\left(\mu+\frac{\mu_{t}}{\sigma_{k}}\right) \frac{\partial k}{\partial x_{j}}\right]+G_{K}+G_{b}-\rho \varepsilon-Y_{M}+S_{K} \text {----------Equation }
$$

and 
International Journal of Design and Manufacturing Technology (IJDMT), ISSN 0976 - 6995(Print), ISSN 0976 - 7002(Online) Volume 1, Issue 1, January-December (2010), @ IAEME

$$
\frac{\partial}{\partial t}(\rho \varepsilon)+\frac{\partial}{\partial x_{i}}\left(\rho \varepsilon u_{i}\right)=\frac{\partial}{\partial x_{i}}\left[\left(\mu+\frac{\mu_{t}}{\sigma_{\varepsilon}}\right) \frac{\partial \varepsilon}{\partial x_{j}}\right]+C_{1 \varepsilon} \frac{\varepsilon}{k}+\left(G_{K}-C_{3 \varepsilon} G_{b}\right)-C_{2 \varepsilon} \rho \frac{\varepsilon^{2}}{k}+S_{\varepsilon}-------
$$

Equation C.9

where,

$G_{K}$ represents the generation of turbulence kinetic energy due to the mean velocity gradients, $G_{b}$ is the generation of turbulence kinetic energy due to buoyancy. $Y_{M}$ represents the contribution of the fluctuating dilatation in compressible turbulence to the overall dissipation rate. $C_{1 \varepsilon}, C_{2 \varepsilon}$ and $C_{3 \varepsilon} . \sigma_{K}$ and $\sigma_{\varepsilon}$ are the turbulent Prandtl numbers for $k$ and $\varepsilon$, respectively. $S_{K}$ and $S_{\varepsilon}$ are defined source terms.

Modelling the Turbulent Viscosity:

The turbulent (or eddy) viscosity, $\mu_{t}$ is computed by combining $k$ and $\varepsilon$ as follows:

$$
\mu_{t}=\rho C_{\mu} \frac{K^{2}}{\varepsilon}-----------------------------------E q u a t i o n ~ C .10
$$

Where, $C_{\mu}$ is a constant. Model Constants are $C_{1 \varepsilon}, C_{2 \varepsilon}, C_{\mu} . \sigma_{K}$ and $\sigma_{\varepsilon}$ have the following default values:

$$
C_{1 \varepsilon}=1.44, C_{2 \varepsilon}=1.92, C_{\mu}=0.09, \sigma_{K}=1.0, \text { and } \sigma_{\varepsilon}=1.3
$$

\subsection{The Realizable $k-\varepsilon$ Model}

The modelled transport equations for $k$ and $\varepsilon$ in the realizable $k-\varepsilon$ model are as follow:

$$
\frac{\partial}{\partial t}(\rho K)+\frac{\partial}{\partial x_{j}}\left(\rho K u_{j}\right)=\frac{\partial}{\partial x_{j}}\left[\left(\mu+\frac{\mu_{t}}{\sigma_{k}}\right) \frac{\partial K}{\partial x_{j}}\right]+G_{K}+G_{b}-\rho \varepsilon-Y_{M}+S_{K} \text {-------Equation }
$$

and

$$
\left.\frac{\partial}{\partial t}(\rho \varepsilon)+\frac{\partial}{\partial x_{j}}\left(\rho \varepsilon u_{j}\right)=\frac{\partial}{\partial x_{j}}\left[\left(\mu+\frac{\mu_{t}}{\sigma_{\varepsilon}}\right) \frac{\partial \varepsilon}{\partial x_{j}}\right]+\rho C_{1} S_{\varepsilon}-\rho C_{2} \frac{\varepsilon^{2}}{K+\sqrt{v \varepsilon}}+C_{1 \varepsilon} \frac{\varepsilon}{K} C_{3 \varepsilon} G_{b}\right)+S_{\varepsilon}
$$

Where,

$$
C_{1}=\max \left[0.43, \frac{\eta}{\eta+5}\right], \eta=S \frac{K}{\varepsilon}, S=\sqrt{2 S_{i j} S_{i j}}
$$

In these equations, $G_{K}$ represents the generation of turbulence kinetic energy due to the mean velocity gradients. $G_{b}$ is the generation of turbulence kinetic energy due to buoyancy. $Y_{M}$ represents the contribution of the fluctuating dilatation in compressible turbulence to the overall dissipation rate. $C_{2}$ and $C_{1 \varepsilon}$ are constants. $\sigma_{K}$ and $\sigma_{\varepsilon}$ are the turbulent Prandtl numbers for $k$ and $\varepsilon$, respectively. $S_{K}$ and $S_{\varepsilon}$ are defined source terms. Note that the $k$ equation is the same as that in the Standard $k-\varepsilon$ 
International Journal of Design and Manufacturing Technology (IJDMT), ISSN 0976 - 6995(Print), ISSN 0976 - 7002(Online) Volume 1, Issue 1, January-December (2010), @ IAEME

model, except for the model constants. However, the form of the $\varepsilon$ equation is quite different from those in the Standard $k-\varepsilon$ models.

Modelling the Turbulent Viscosity

As in The Standard $k-\varepsilon$ models, the eddy viscosity is computed from:

$$
\begin{aligned}
\mu_{t} & =\rho C_{\mu} \frac{K^{2}}{\varepsilon}-1 \\
C_{\mu} & =\frac{1}{A_{0}+A_{s} \frac{K U^{*}}{\varepsilon}}
\end{aligned}
$$

Where,

$$
U^{*}=\sqrt{S_{i j} S_{i j}+\overline{\Omega_{i j}} \overline{\Omega_{i j}}}
$$

and

$$
\overline{\Omega_{i j}}=\Omega_{i j}-2 \varepsilon_{i j k} w_{K}, \Omega_{i j}=\overline{\Omega_{i j}}-\varepsilon_{i j k} w_{K} \text {------------------ Equation C.16 }
$$

where $\overline{\Omega_{i j}}$ is the mean rate-of-rotation tensor viewed in a rotating reference frame with the angular velocity $w_{K}$. The model constants $A_{0}=4.04, A_{s}=\sqrt{6 \cos \phi}$.

Where,

$$
\phi=\frac{1}{3} \cos ^{-1}(\sqrt{6 W}), W=\frac{S_{i j} S_{j k} S_{k i}}{\overline{S^{3}}}, \bar{S}=\sqrt{S_{i j} S_{i j}}, S_{i j}=\frac{1}{2}\left(\frac{\partial u_{j}}{\partial x_{i}}+\frac{\partial u_{i}}{\partial x_{j}}\right) \text {-----Equation C.17 }
$$

$C_{\mu}$ is a function of the mean strain and rotation rates, the angular velocity of the system rotation, and the turbulence fields ( $k$ and $\varepsilon$ ).

The model constants are;

$$
C_{1 \varepsilon}=1.44, C_{2}=1.9, \sigma_{k}=1.0, \sigma_{\varepsilon}=1.2
$$

\subsection{Reynolds stress transport model}

The exact transport equations for the transport of the Reynolds stresses, $\overline{\rho u_{i}^{\prime} u_{j}^{\prime}}$, may be written as follows:

Local Time Derivative + Convection $=-$ Turbulent Diffusion + Molecular Diffusion Stress Production - Buoyancy Production + Pressure Strain - Dissipation - Production by Rotation + Source Terms

$$
\begin{aligned}
& \left.\frac{\partial}{\partial t}\left(\rho \overline{u_{i}^{\prime} u_{j}^{\prime}}\right)+\frac{\partial}{\partial x_{k}}\left(\rho u k \overline{u_{i}^{\prime} u_{j}^{\prime}}\right)=-\frac{\partial}{\partial x_{k}}\left(\rho \overline{u_{i}^{\prime} u_{j}^{\prime} u_{k}^{\prime}}\right)+\overline{p\left(\delta_{k j} u_{i}^{\prime}+\delta_{i k} u_{j}^{\prime}\right.}\right)+\frac{\partial}{\partial x_{k}}\left[\mu \frac{\partial}{\partial x_{k}} \overline{\left(u_{i}^{\prime} u_{j}^{\prime}\right.}\right]- \\
& \rho\left(\overline{u_{i}^{\prime} u_{k}^{\prime}} \frac{\partial u_{j}}{\partial x_{k}}+\overline{u_{i}^{\prime} u_{j}^{\prime}} \frac{\partial u_{i}}{\partial x_{k}}\right)-\rho \beta\left(g_{i} \overline{u_{j}^{\prime} \theta}+g_{j} \overline{u_{i}^{\prime} \theta}\right)+p\left(\frac{\partial u_{i}^{\prime}}{\partial x_{j}}+\frac{\partial u_{j}^{\prime}}{\partial x_{i}}\right)-2 \mu \frac{\partial u_{i}^{\prime}}{\partial x_{k}} \frac{\partial u_{i}^{\prime}}{\partial x_{k}}- \\
& 2 \rho \Omega_{k}\left(\overline{u_{j}^{\prime} u_{m}^{\prime}} \varepsilon_{i k m}+\overline{u_{i}^{\prime} u_{m}^{\prime}} \varepsilon_{j k m}\right)+S_{\text {source }}
\end{aligned}
$$

Where,

$\rho$ is density of fluid, $u_{i}^{\prime}, u_{j}^{\prime}, u_{k}^{\prime}$ are velocity fluctuation in direction $x_{i}^{\prime}, x_{j}^{\prime}, x_{k}^{\prime}$ respectively, $k$ is kinetic energy, $\varepsilon$ is a dissipation tensor, $\beta$ is thermal expansion, $\mu$ is viscosity, $\mathrm{g}$ is gravity, $\Omega$ is the rotation and $\theta$ is an angle of strain.

\section{RESULTS AND DISCUSSION}


International Journal of Design and Manufacturing Technology (IJDMT), ISSN 0976 - 6995(Print), ISSN 0976 - 7002(Online) Volume 1, Issue 1, January-December (2010), @ IAEME

\subsection{Temperature profile simulation in the drying chamber of spray dryer}

In this section, the temperature and velocity distribution of the hot air inside the drying chamber for different conditions (temperature and air velocity) were studied. The three different levels of temperature $(398,421$, and 461K) and velocity $(12.7,14.6$ and $16.6 \mathrm{~m} / \mathrm{s}$ ) were used to analyse the temperature profile and velocity vector inside the spray dryer. The temperature levels were selected on the basis of temperature range available on the spray dryer and maintained to gives sufficient evaporation. The velocity levels were chosen to cover the whole range of hot air velocity available by the spray dryer to find out its effect on flow rate in the spray drying of the thermal spray powder slurry. These models were simulated according to the condition of hot air coming in from the top of the drying chamber. Initially the heat transfer coefficient was found to be $0.25 \mathrm{~W} / \mathrm{m}^{2} . \mathrm{K}$ for each model, which was in good agreement with the real conditions of the spray dryer [19]. Experimentally the spray dryer would be left to heat until the outlet and inlet temperatures reach the set temperatures (for example inlet temperature $398 \mathrm{~K}$ and outlet temperature $373 \mathrm{~K}$ ) and then spray drying would start, so the simulations were carried out in the same way. The amount of hot air defines how much heat enters in the main drying chamber and its profile gives an idea of where evaporation occurs inside the dryer. The velocity vector shows the circulation and movement of the hot air, which would both directly affect the quality of the dried product and be responsible for the evaporation of the liquid. For all of these inlet conditions, the drying chamber was simulated using the three turbulent models, Standard $K-\epsilon$, Realizable $K-\epsilon$ and RSM and later these were compared experimentally to predict the best results.

Figure 6 shows an example of one of these results inlet temperature for $398 \mathrm{~K}$ at a hot air velocity of $12.7 \mathrm{~m} / \mathrm{s}$. Table 1 shows the temperature the found at different zones (see Figure 5.22 (a)) in the chamber where different velocities were used.

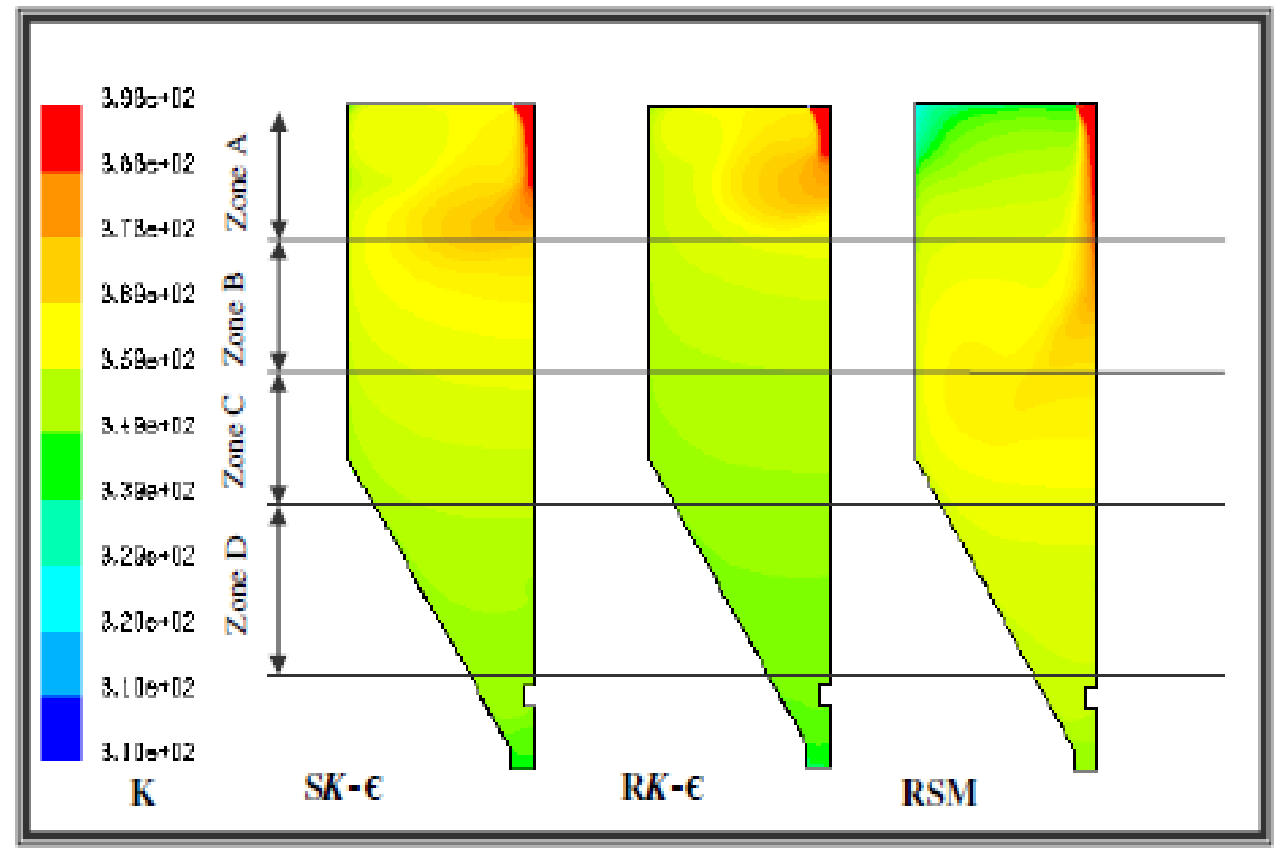

Figure 6: Temperature profile by $\mathrm{S} K-\mathrm{c}, \mathrm{R} K-\mathrm{c}$ and $\mathrm{RSM}$ methods (inlet condition Temp-398 K, velocity-12.7m/s)

Table 1: Mean zone temperatures found for varying hot air velocities 
International Journal of Design and Manufacturing Technology (IJDMT), ISSN 0976 - 6995(Print), ISSN 0976 - 7002(Online) Volume 1, Issue 1, January-December (2010), @ IAEME

\begin{tabular}{|c|c|c|c|c|c|c|c|c|c|c|}
\hline \multirow{2}{*}{$\begin{array}{l}\text { Hot air } \\
\text { Velocity }\end{array}$} & \multirow[t]{3}{*}{ Zones } & \multicolumn{9}{|c|}{ Input Temperatures (K) } \\
\hline & & \multicolumn{3}{|c|}{ Setting 398K } & \multicolumn{3}{|c|}{ Setting $421 \mathrm{~K}$} & \multicolumn{3}{|c|}{ Setting 461K } \\
\hline \multirow{5}{*}{$\begin{array}{l}12.7 \\
(\mathrm{~m} / \mathrm{s})\end{array}$} & & $\mathbf{S} K-\mathbf{c}$ & $\mathbf{R} K-\mathbf{c}$ & RSM & $\mathbf{S} K-\mathbf{c}$ & $\mathbf{R} K-\mathbf{c}$ & RSM & SK-c & $\mathbf{R} K-\mathbf{c}$ & RSM \\
\hline & A & 378 & 369 & 388 & 380 & 393 & 403 & 421 & 429 & 439 \\
\hline & B & 355 & 350 & 365 & 371 & 370 & 383 & 403 & 395 & 417 \\
\hline & $\mathbf{C}$ & 350 & 344 & 362 & 366 & 361 & 376 & 386 & 386 & 403 \\
\hline & D & 345 & 341 & 352 & 359 & 356 & 364 & 379 & 376 & 401 \\
\hline \multirow{4}{*}{$\begin{array}{c}14.6 \\
(\mathrm{~m} / \mathrm{s})\end{array}$} & $\mathbf{A}$ & 384 & 376 & 384 & 387 & 396 & 406 & 424 & 433 & 440 \\
\hline & B & 368 & 364 & 369 & 379 & 382 & 394 & 408 & 403 & 421 \\
\hline & $\mathbf{C}$ & 362 & 354 & 364 & 376 & 371 & 387 & 394 & 388 & 406 \\
\hline & D & 357 & 351 & 356 & 371 & 368 & 376 & 380 & 379 & 388 \\
\hline \multirow{4}{*}{$\begin{array}{c}16.6 \\
(\mathrm{~m} / \mathrm{s})\end{array}$} & $\mathbf{A}$ & 386 & 374 & 392 & 399 & 399 & 409 & 434 & 433 & 446 \\
\hline & B & 374 & 369 & 372 & 389 & 392 & 394 & 415 & 418 & 423 \\
\hline & $\mathrm{C}$ & 367 & 359 & 370 & 377 & 384 & 391 & 396 & 403 & 410 \\
\hline & D & 362 & 355 & 363 & 374 & 379 & 376 & 388 & 396 & 395 \\
\hline
\end{tabular}

\section{* Range of standard deviation \pm 2.75 to 4.50 .}

The temperature profile results for each inlet temperature (398K) and increasing velocity $(12.7,14.6$ and $16.6 \mathrm{~m} / \mathrm{s})$, showed that the hot region increased with an increased in velocity. The temperature profile for the Standard $K-\epsilon$ method at a velocity $12.7 \mathrm{~m} / \mathrm{s}$, showed the hot region developed from the inlet point to Zone A axially downwards while this region increased to Zone B when the velocity was increased to $14.6 \mathrm{~m} / \mathrm{s}$; and to $0.7 \mathrm{~m}$ (Zone B) with the increase of hot air to $16.6 \mathrm{~m} / \mathrm{s}$. The Realizable $K-\epsilon$ method for the same conditions was slower to develop, with the hot region ending at $0.2 \mathrm{~m}$ and remaining in Zone A upto $16.1 \mathrm{~m} / \mathrm{s}$. Whereas the RSM method hot region started in Zone B and increased with higher velocity but not to the same extent as that for the standard $K-\epsilon$ method results. A similar observation was found when the temperature input was increase from 398 to 421 and $461 \mathrm{~K}$ for all three models. This shows that the temperature profile is dependent on the velocity vector, as the velocity vector carries heat from the source. However, along the axis of the spray dryer, the temperature gradient line is almost same by these turbulent models (Figure 7). The temperature of central axis area is an important as major drying process of HA droplet was done there. Figure 7 shows $\mathrm{R} K$ - $\epsilon$ predict the temperature gradient along the axis is highest as compared with RSM which has the lowest due to narrow temperature distribution. 
International Journal of Design and Manufacturing Technology (IJDMT), ISSN 0976 - 6995(Print), ISSN 0976 - 7002(Online) Volume 1, Issue 1, January-December (2010), @ IAEME

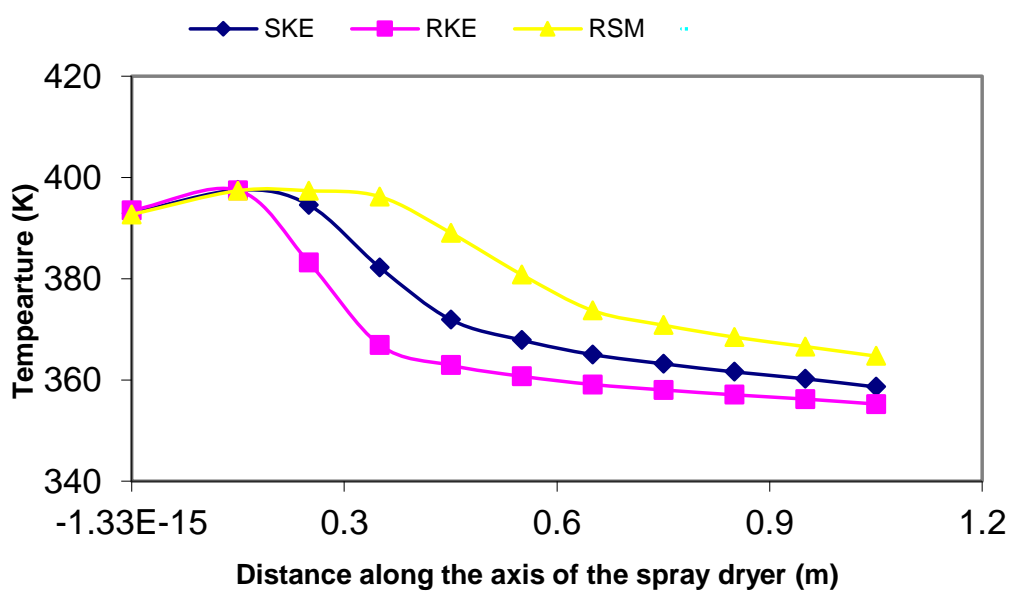

\section{Figure 7: Temperature gradient along the axis of the spray dryer (inlet condition; temperature 398K and Velocity $12.7 \mathrm{~m} / \mathrm{s}$ )}

In general all graphs show that the velocity vector increased from its inlet velocity $12.7,14.6$ and $16.6 \mathrm{~m} / \mathrm{s}$ at the constant temperature in each $\mathrm{S} K-\epsilon, \mathrm{R} K-\epsilon$ and RSM models respectively. It has been shown that the inlet hot air is responsible for the distribution the heat inside the spray dryer, which affects the movement of the spray dried particles. In the Standard $K-\epsilon$ method, (Figure 8) a maximum vector of $23.8 \mathrm{~m} / \mathrm{s}$ was attained at the outlet of the spray dryer and had three circulations regions; one at the corner of the roof and two on side the walls of the spray dryer. The Realizable $K-\epsilon$ had a maximum vector $22.2 \mathrm{~m} / \mathrm{s}$ (Figure 9) and again three circulations with one more dominated at the corner of the spray dryer. Whereas the RSM, had a maximum vector of $24.5 \mathrm{~m} / \mathrm{s}$ (Figure 10) at the outlet, but due to its narrow distribution velocity down the centre of the chamber, the three areas of circulations were located in different regions to that found in the Standard $K-\epsilon$ and Realizable $K-\epsilon$ methods.

The temperature profile produced was quite different in each of the three turbulent models; Standard $K-\epsilon$, Realizable $K-\epsilon$ and RSM methods. Inspite of the different turbulent models, the temperature profile depended on the flow rate of the hot air. At an inlet hot velocity of $16.6 \mathrm{~m} / \mathrm{s}$ a maximum wide distribution of temperature resulted regardless of inlet temperature, however, at $12.7 \mathrm{~m} / \mathrm{s}$ a minimum distribution was found. For fast and uniform drying, it is recommended [20], to have a uniform temperature profile and more turbulent hot air flow, so on this basis the hot air at 16.6 $\mathrm{m} / \mathrm{s}$ velocity and inlet temperature $461 \mathrm{~K}$ would give the best drying rate of HA slurry. The temperature profile using the Realizable $K$ - $\epsilon$ method was selected for the atomisation of the HA slurry as its temperature profile was more uniform, less computational expensive and incorporated swirl motion [21-25] as will be shown in section 5.6. 
International Journal of Design and Manufacturing Technology (IJDMT), ISSN 0976 - 6995(Print), ISSN 0976 - 7002(Online) Volume 1, Issue 1, January-December (2010), @ IAEME

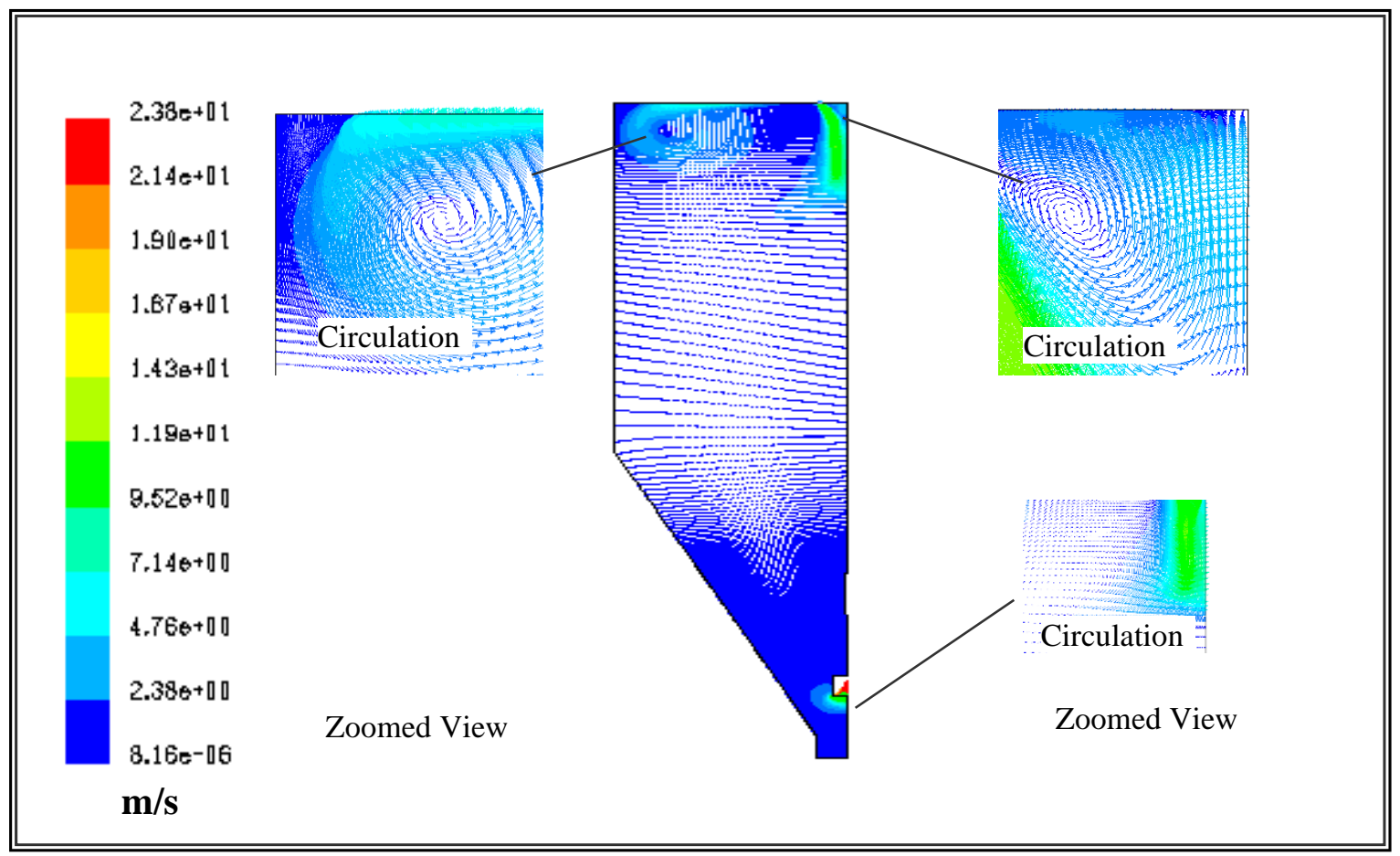

Figure 8: Velocity vector using the $S K$-c methods (inlet condition Temp-398 K, velocity $-12.7 \mathrm{~m} / \mathrm{s}$ )

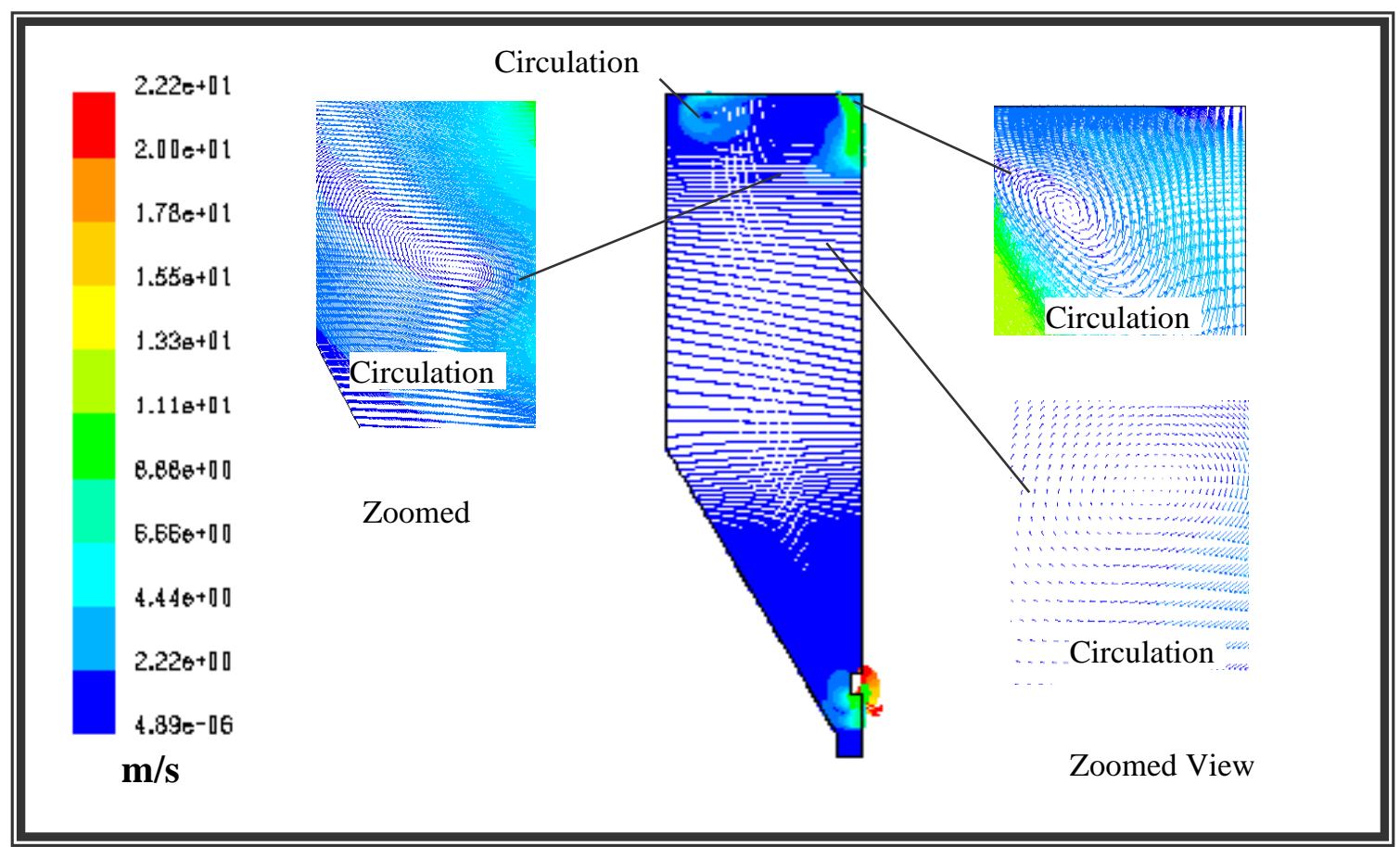

Figure 9: Velocity vector using the $\mathrm{R} K-\mathrm{c}$ method (inlet condition Temp-398 K, velocity- $12.7 \mathrm{~m} / \mathrm{s}$ ) 


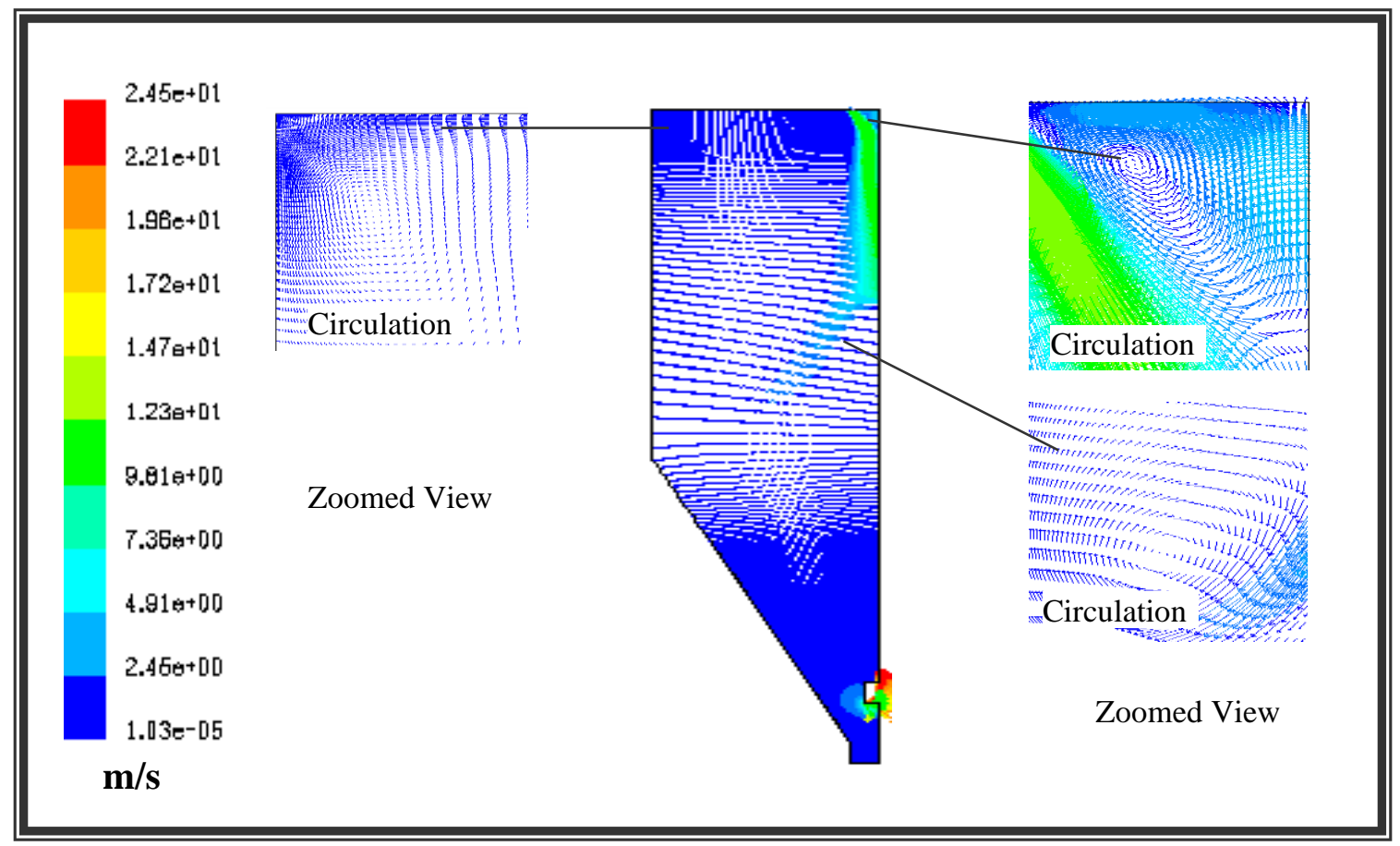

\section{Figure 10: Velocity vector by RSM method (inlet condition Temp-398 K, velocity-12.7m/s)}

\subsection{Temperature profile comparison}

The temperature profile was very important in the main spray drying chamber as the evaporation of the fluid/water in the slurry of thermal spray powder depends upon the occupation of the slurry in various temperature zones. The temperature measurement had the two approaches: one can measure with an unprotected probe and the second is protecting probe [26], subsequently, the probe must be cleaned before another measurement cycle can begin. The time span over which actual temperatures can be measured using an unprotected probe are limited by the temperature equilibration of the probe and the rate of particle deposition. This meant that in most sprays the response time of the probe should be very short while the density of the spray should be low. The other approach is to prevent the probe from begin hit by droplets [26]. Avoiding wetting of the probe, requires placing a shield over the probe, and these vary from simple shields to so-called aspirated probes. Papadakis [20] used a simple shield to protect the probe from being hit by droplets mainly from one direction only. It is clear that such arrangements do not work in flow systems with circulations or large eddies. Goldberg [27] developed a shield to protect the probe from particles coming from all directions. In such arrangements the problems arises that the probe is also measuring the temperature surrounded by the cooler walls of the shield. To avoid this, Nijhhawan et al. [28] described that the shield should be aspirated. Kieviet et al. [29] developed a temperature and humidity device which was based on protecting the temperature probe from being hit by particles by removing the particles from the gas stream. This was good in the sense that it gave results for the two air parameters, but gave no results for the effect on the particles themselves. Rainbow refractometry has been used to measure the temperature of droplets which is based on the refractive index that is a function of temperature, because the density changes in condensed materials with changes in temperature [29]. Gemic et al. [30] measured the temperature using 
International Journal of Design and Manufacturing Technology (IJDMT), ISSN 0976 - 6995(Print), ISSN 0976 - 7002(Online) Volume 1, Issue 1, January-December (2010), @ IAEME

such a method. This method gave good results because the device doesn't come in contact with droplets. However, due to constraint of spray dryer chamber a simpler procedure was adopted. In this research, the temperature profiles were measured by using $\mathrm{K}$ type thermocouples (range -50 to $1000{ }^{\circ} \mathrm{C}$ and accuracy $\pm 2{ }^{\circ} \mathrm{C}$ ) at different points inside the main drying chamber (Figure 11 and 12). For that a mesh was designed and placed inside the chamber to hold the thermocouples at fixed positions. The thermocouples extension wires were taken out from the gasket of the drying chamber roof to measure the temperature at the different points. Then, lid was place to seal the drying chamber. The spray dryer was then run without the feed. The temperature was recorded at 15 point at one time when the inlet and outlet temperatures reached at the set value (for example inlet temperature $461 \mathrm{~K}$ and outlet temperature $383 \mathrm{~K}$ ) and stabilised for 10 minutes.

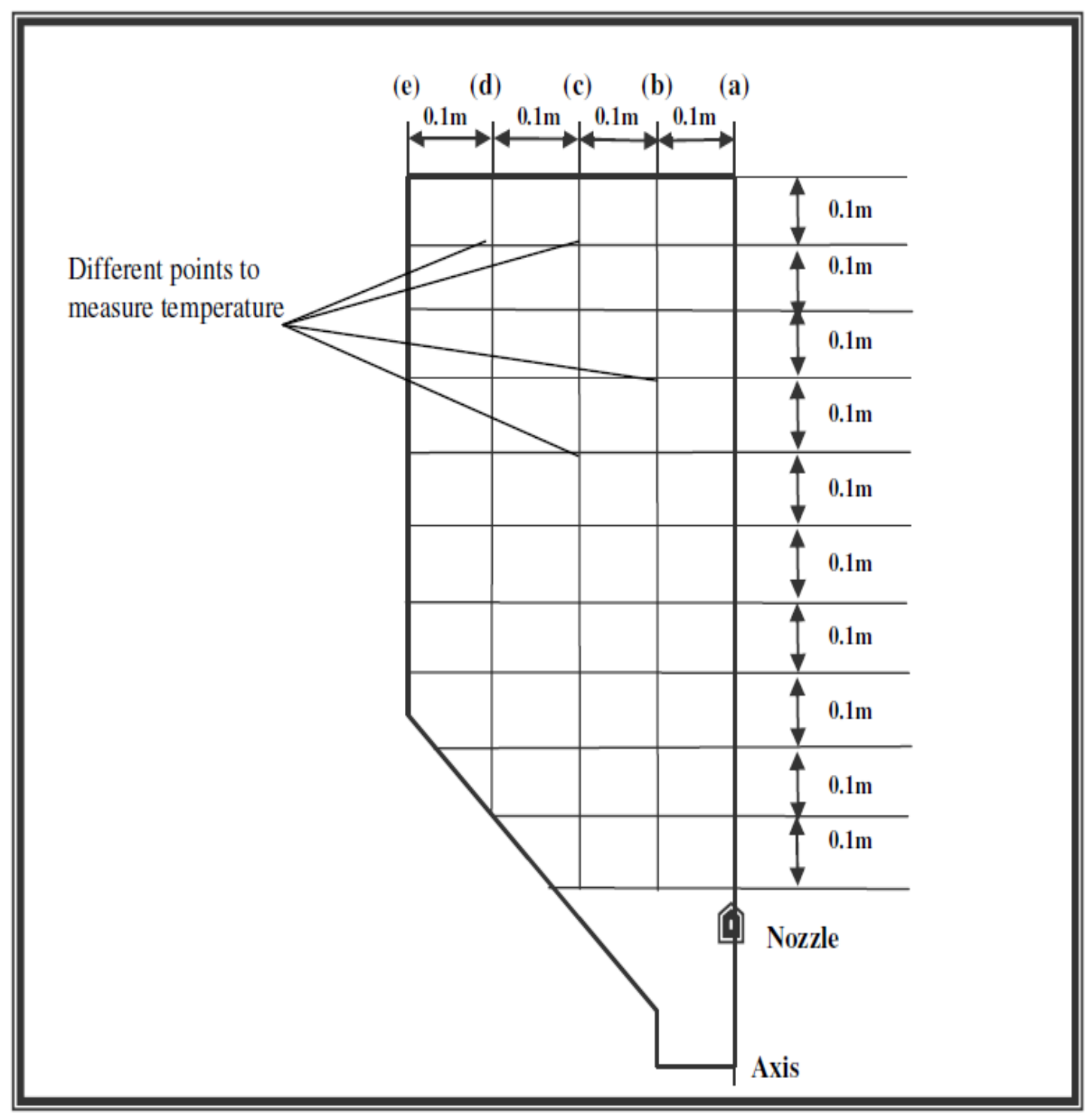

Figure 11: Mesh points used to measure the temperature experimentally 
International Journal of Design and Manufacturing Technology (IJDMT), ISSN 0976 - 6995(Print), ISSN 0976 - 7002(Online) Volume 1, Issue 1, January-December (2010), @ IAEME

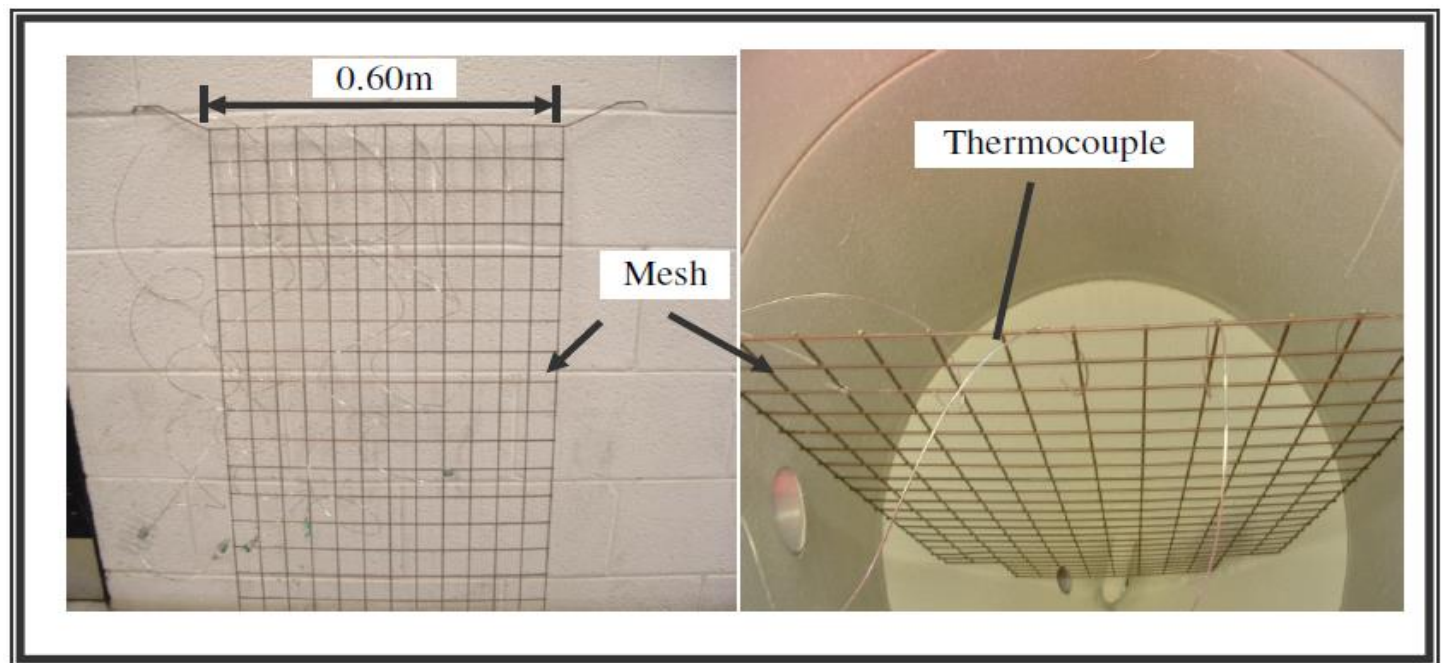

Figure 12: Mesh to hold the thermocouple inside the spray dryer to measure the temperature profile

The temperature results measured experimentally at different points in the chamber (Figure 12). Figure 13 shows the results found for an input temperature and velocity of $398 \mathrm{~K}$ and $12.7 \mathrm{~m} / \mathrm{s}$ respectively. Results (a) to (e) show the temperatures found going from the top of the chamber towards the two nozzle assembly, at for different positions in the chamber. The results (experimentally and simulated) all decreased from the top of the chamber towards the nozzle.

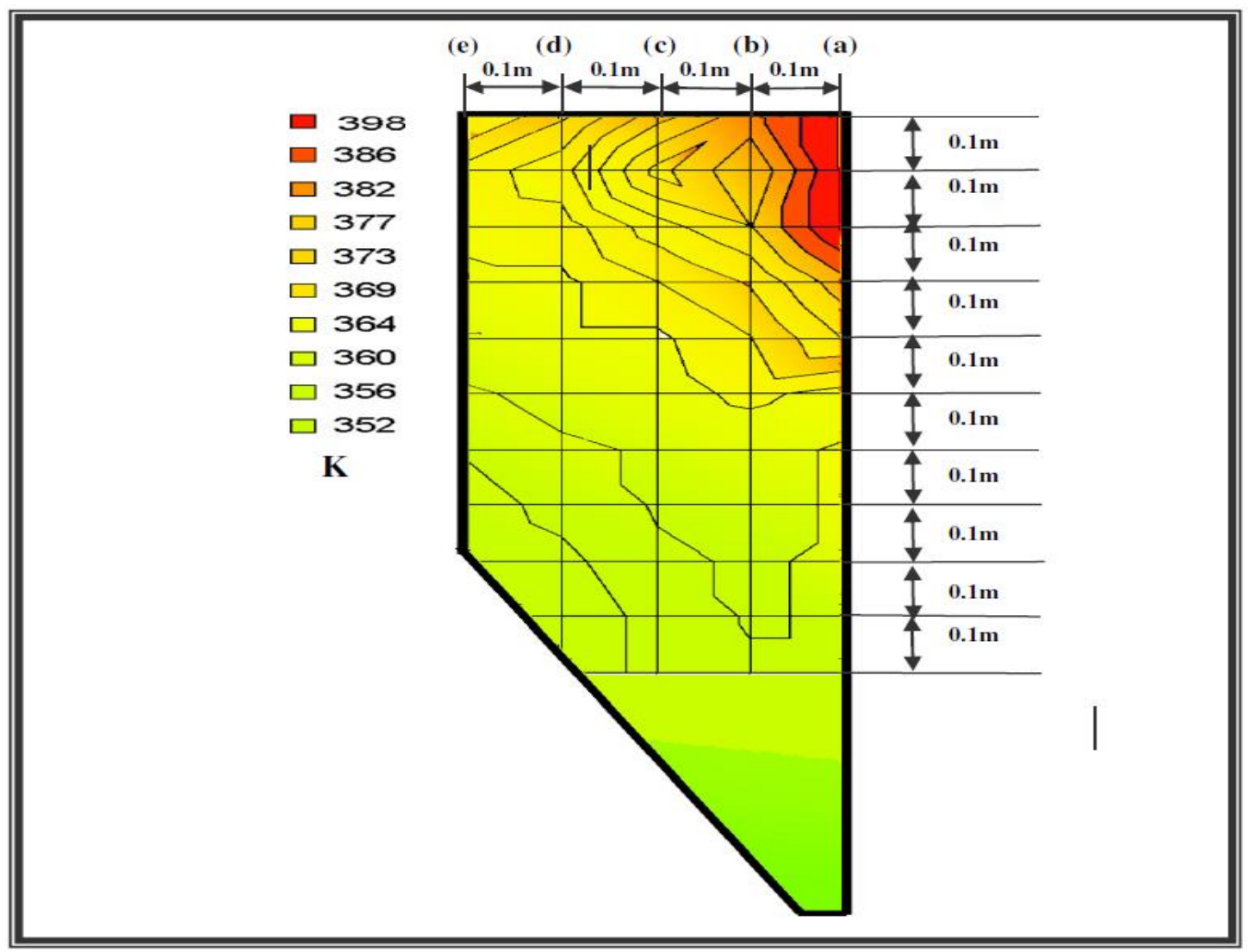

Figure 13: Temperature profile measured experimentally (inlet condition tem$398 \mathrm{~K}$, velocity-12.7m/s) 
International Journal of Design and Manufacturing Technology (IJDMT), ISSN 0976 - 6995(Print), ISSN 0976 - 7002(Online) Volume 1, Issue 1, January-December (2010), @ IAEME

The Measurement results and the simulation results did not differ by a major amount (maximum difference was approximately 20\%). The major difference in temperature profiles was found particularly at the inlet point of the hot air. However, at the middle part of drying chamber each model produced results close in range to that found experimentally (Figure 14 and 15). The measured values at the top of spray dryer were much higher in all cases as hot air comes down from the top. But at the middle section of the drying chamber, the measured values were very close to the simulations values. Many researcher have [31-33] shown the temperature profile to be in good agreement with the Standard $K-\epsilon$ method, but this method does not simulate swirl movement which is common in the spray drying processes to disperse the feed spray more uniformly in contact with the hot air [33]. To incorporate the swirl inside the spray dryer, one has only two options; the Realizable $K-\epsilon$ and RSM method, however the Realizable $K$-e method provides more promising results [34]. Though the Reynolds stress model (RSM) is the most descriptive turbulence model, the reliability of RSM predictions is still limited by closure assumptions (modelling of the pressure-strain and dissipation-rate) employed by the model [35]. Thus why the RSM may not always yield results that are clearly superior to the Standard $K-\epsilon$ and Realizable $K-\epsilon$ models in all classes of flows, to warrant the additional computational expense.

Figure 15 shows that the Standard $K-\epsilon$ and Realizable $K-\epsilon$ produced results are close to that found from the experimental data. The Realizable $K$ - $\epsilon$ method simply combines the Boussinesq relationship and an eddy viscosity definition to obtain the normal Reynolds stress in an incompressible strained mean flow, and its eliminates the few deficiency that exist in the Standard $K-\epsilon$ method like the prediction of the spreading rate for axisymmetric model [36].

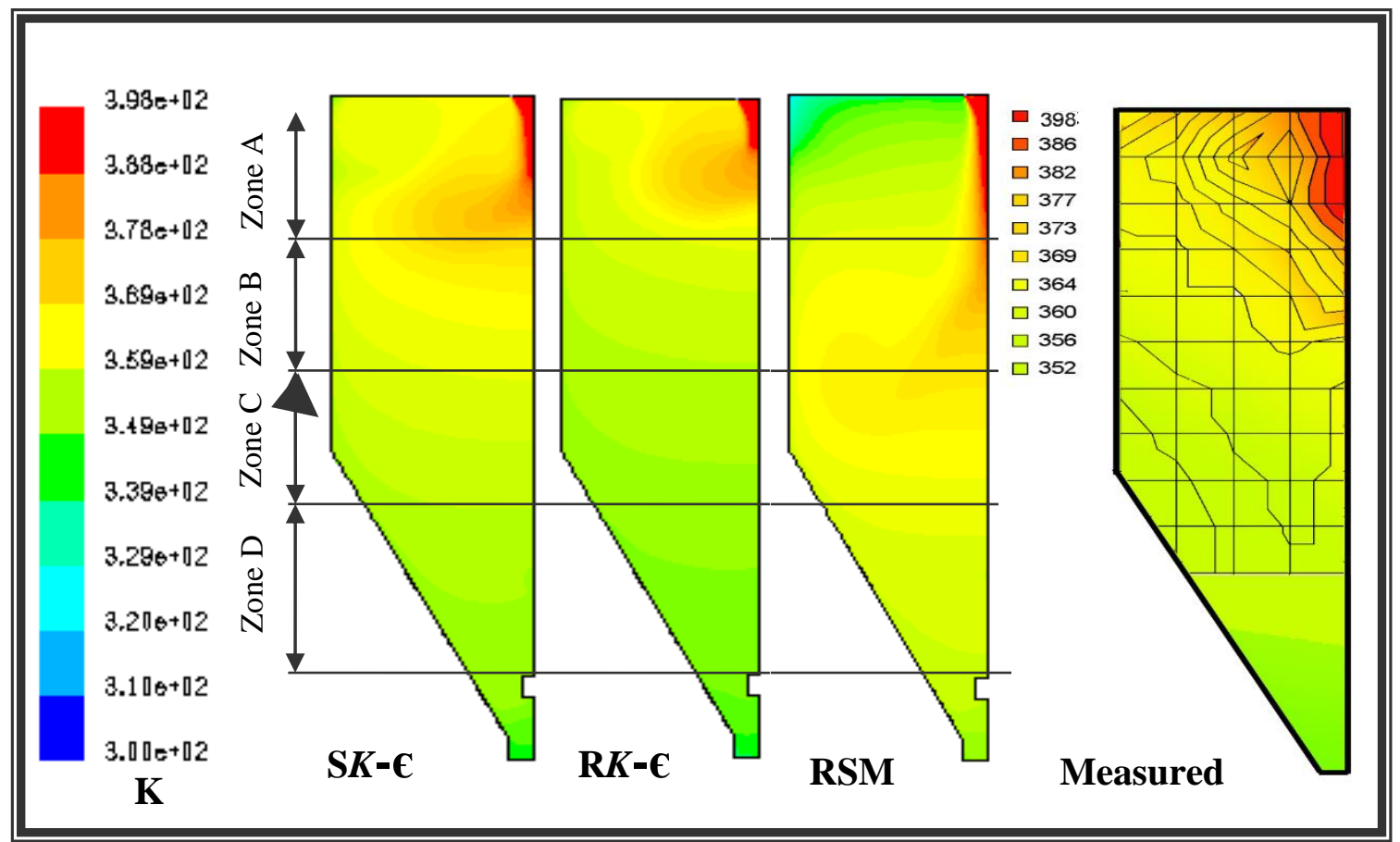

Figure 14: Temperature profile by $S K-\epsilon, R K-c$ and measured (inlet condition tem-398 $\mathrm{K}$, velocity- $12.7 \mathrm{~m} / \mathrm{s}$ ) 
International Journal of Design and Manufacturing Technology (IJDMT), ISSN 0976 - 6995(Print), ISSN 0976 - 7002(Online) Volume 1, Issue 1, January-December (2010), @ IAEME

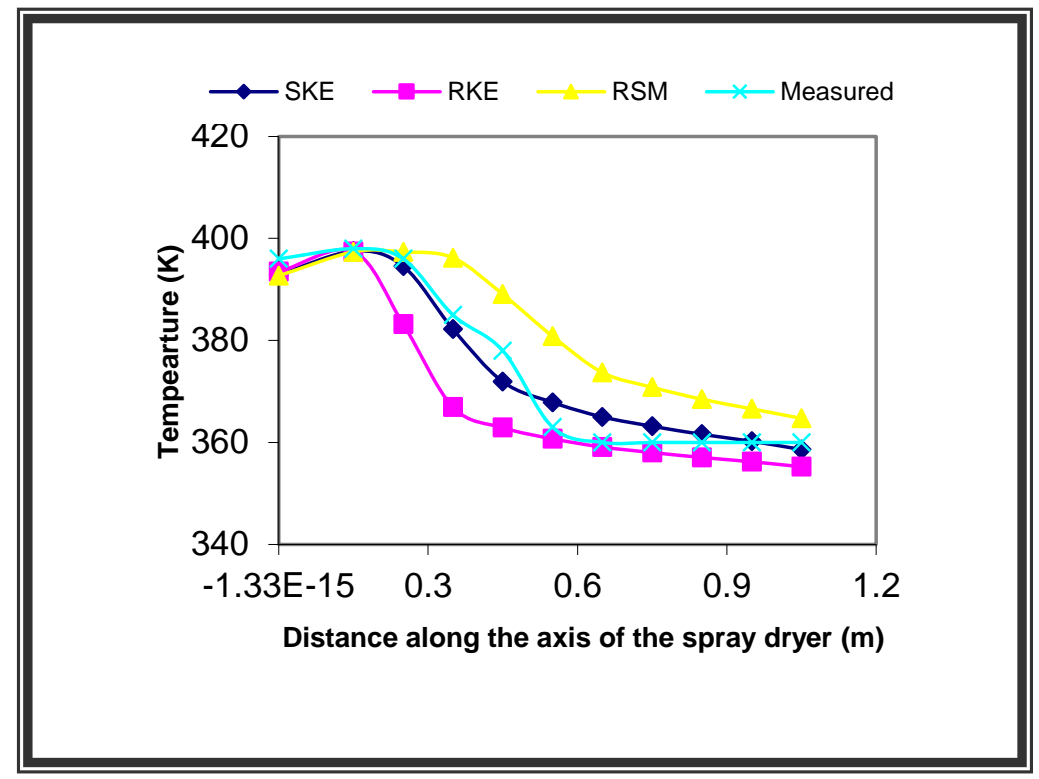

Figure 15: Comparison of temperature gradient along the axis inside the spray dryer (inlet condition; temperature $398 \mathrm{~K}$ and Velocity $12.7 \mathrm{~m} / \mathrm{s}$ )

\section{CONCLUSION}

During the spray dryer temperature profile modelling, the simulation and measurement results did not differ by a major amount (maximum difference was approximately $9.0 \%$ ). The Standard $K-\epsilon$ and Realizable $K-\epsilon$ produced results closer to that of the experimental data. To incorporate the swirl inside the spray dryer, the Realizable $K$-e method, provided more promising results than the RSM method Knowledge of the aforementioned mechanisms, will aid researchers and industrialists to select ideal input parameters to produce HA particles with the desired size and morphologies. This will not only benefit thermal spray powders but also provide more efficiency during the process, without the associated loss of produced material currently been experienced in industry. From a scale up principle, this CFD analysis can be applied to any size of spray dryer, or in the analysis of new designs. This procedure of analysis would save time and money in the analysis of industrial spray dryer units.

\section{REFERENCES}

1 ASM, Metal Handbook, "Powder Metal Technologies and Application" $1^{\text {st }}$ ed., 7, (1998).

2 Wei-Cheng Lih, et al., "Effects of Process Parameters on Molten Particle Speed and Surface Temperature and the Properties of HVOF CrC/NiCr Coatings", Surface and Coatings Technology, 133-134, (2000), pp. 54-60.

3 Wigren, J. et al., "Effect of Powder Morphology, Microstructure, and Residual Stresses on Thermal Barrier Coating Thermal Shock Performance", National Thermal Spray Conference, USA, (1996), pp. 855-861. 
International Journal of Design and Manufacturing Technology (IJDMT), ISSN 0976 - 6995(Print), ISSN 0976 - 7002(Online) Volume 1, Issue 1, January-December (2010), @ IAEME

4 Pawlowski, L., "The Science and Engineering of Thermal Spray Coatings", John Wiley \& Sons; 1st ed. ISBN: 0471952532, (1995).

5 Stokes, J., "Production of Coated and Free Standing Engineering Components using the HVOF (High Velocity Oxy-Fuel) Process", Ph D. Thesis, Dublin City University, Ireland, (2003).

6 Chistopher, C. B., "Materials Production for Thermal Spray Processes- A Lesson From Thermal Spray Technology" ASM, The Materials Information Society, USA, (1998).

7 Britton, C. R., "Manufacturing Methods and Quality Control Procedures for Thermal Spray Powders", Metco Ltd., Metal Powder Report, 47 (3), (1992), pp. 62-63.

8 Houck, D.L., "Thermal Spray: Advances in Coatings Technology", Published ASM Intl. USA, (1989).

9 Masters, K., "Spray Drying Handbook", 4th ed., George Gowdin, London, ISBN 0-7114-5805-7 (1985).

10 Bertrand, G., et al., "Spray-Dried Ceramic Powders: A Quantitative Correlation Between Slurry Characteristics and Shapes of the Granules" Chemical Engineering Science Vol. (1) 60, (2005), pp. 95-102.

11 Haung, L. and Mujumdar, A.S., "classification and Selection of Spray Dryer, Chemical Industry Digest (India), vol. 7-8, (2003), pp.75-84.

12 Mujumdar, A.S., "Advance in Drying", Vol. 1, Hemisphere Publishing Corporation, USA, ISBN 0-89116-185-6, (1980).

13 Gauvin, W. H. and Katta, S., "Basic Concepts of Spray Drying Design", American Institute of Chemical Engineers, Vol. (4) 22, (1976), pp.713-724.

14 Crowe, C.T., "Modelling Spray -Air Contact in Spray-Drying Systems", Journal Advances in Drying1, Vol. 1, (1980), pp. 63-99.

15 Walton, D.E. and Mumford, C.J, "Spray Dried Products: Characterization of Particle Morphology", Trans International Chemical Engineering, Vol. 77, (1999), pp 21-33.

16 Thakker, A. and Hourigan, F., "Technical Note; A Comparison of Two Schemes for CFD Analysis of the Impulse Turbine for Wave Energy", Renewable Energy, Vol. (9) 30, ( 2005), pp. 1401-1410.

17 Bastarrica, M.C. and Kaher, H.N., "Designing a Product Family of Meshing Tools", Advances in Engineering Software, (2005), pp. 1-10.

18 Ferziger, J.H, Peric, M., "Computational Methods for Fluid Dynamics", $3^{\text {rd }}$ ed., Springer, New York, ISBN-3-540-42074-6, (2002).

19 Huang. L., et al., "Computational Fluid Dynamic Simulation of Droplet Drying in a Spray Dryer", Drying 2004, Brazil, (2004), pp.326-332.

20 Papadakis, S. E., "Air Temperatures and Humidities in Spray Drying”, Ph.D. Thesis, University of California, Berkeley, USA, (1987).

21 Harvine, D.J.E., Langrish, T. A. G., and Fletcher, D. f., “A Computational Fluid Dynamics study of a Tall-form Spray Dryer", Institution of Chemical Engineers. Vol. (c) 80, (2002), pp. 163-175.

22 Langrish, T. A. G., and Kockel, T.K., "The Implementation of a Characteristic Drying Curve for Milk Powder using a Computational Fluid Dynamics Simulation", Chemical Engineering Journal, Vol. (1) 84, (2000), pp. 69-74.

23 Verdurmen. R.E.M., et al. "Modelling Spray Drying Processes for Diary Products" 1st International Symposium on Spray Drying of Milk Products, Rennes, France, (2001), pp.453-463. 
International Journal of Design and Manufacturing Technology (IJDMT), ISSN 0976 - 6995(Print), ISSN 0976 - 7002(Online) Volume 1, Issue 1, January-December (2010), @ IAEME

24 Fletcher, D.F., et al. "What is important in the simulation of spray dryer performance and how do current CFD models perform?", Applied Mathematical Modelling Vol. 30 (2006), 1281-1292.

25 Vikram S. S. and Hoo K. A. "Optimum controller design for a spray drying process" Control Engineering Practice, Vol.16 (2008) 541-552.

26 Fieg, G., Wonzny, G., and Jeromin, L., "Estimation of the Drying Rate and Moisture Profiles in an Industrial Spray Dryer by Means of Experimental Investigations and a Simulation Study", Chemical Engineering and Technology, Vol. 17, (1994), pp. 235-241.

27 Goldberg, J., "Modelling of Spray Dryer Performance" PhD Thesis, University of Oxford, United Kingdom, (1987).

28 Nijhawan, S., et al., "Measurement of Vapour Superheat in Post-Critical-Heat Flux boiling", Journal of Heat Transfer, Vol. 102, (1980), pp 465-469.

29 Kievit, F.G., et al., "A Device for Measuring Temperature and Humidity in a Spray Drying Chamber” Trans International Chemical Engineering, Vol. 75 (A), (1997), pp. 29-38.

30 Gemci, T., Hom, J., and Chigier, H., "Simulations of Evaporating Spray and Comparison with Droplet Temperature Measurement obtained by Rainbow Refractometer", Proceedings of ASME-Fluid Engineering Division, Vol. 253, (2000), pp. 59-66.

31 Sommerfeld, M. and Qiu, H., "Detailed Measurements in a Swirling Particulate Two-Phase Flow by a Phase Doppler Anemometer" International Journal Heat and Fluid Flow, Vol. 12, (1991), pp. 20-28.

32 Takeuchi, G., et al., "Spatial Distributions of droplet Size and Velocity in Air Heated Spray Measured by Interferometric Laser Imaging Technique", 12th International Symposium on an Application of Laser Techniques to Fluid Mechanics, Lisbon, (2004).

33 Kobayashi, T., Kawaguchi, T. and Meada, M., "Measurement of Spray Flow by an Improved Interferometric Laser Imaging Droplet Sizing System" 10th International Symposium on an Application of Laser Techniques to Fluid Mechanics, Lisbon, (2002).

34 Fluent Inc. FLUENT 6.2.3 User Guide, Vol. 1-6, Published by FLUENT Inc., Lebanon, New Hampshire, USA, (2009).

35 Lanunder, B.E., Reece, G.J. and Rodi, W., "Progress in the Development of a Reynolds Stress Turbulence Closure", Journal of Fluid Mechanics, Vol. 3, (1975), pp. 537-566.

36 Yakhot and Orszag, S. A., "Renormalization Group Analysis of Turbulence: I. Basic Theory", Journal of Scientific Computing, Vol. 1, (1986), pp. 1-51. 